\title{
Linked Data
}

\section{Compiled by Anna Appleman}

Ali, Irfan and Nosheen Fatima Warraich. "Linked Data Initiatives in Libraries and Information Centres: A Systematic Review." Electronic Library 36, no. 5 (October 2018): 925-37.

Schreur, Philip. "RDA, Linked Data, and the End of Average." JLIS.it 9, no. 1 (2018). DOI: http:// dx.doi.org/10.4403/jlis.it-12448

Smith-Yoshimura, Karen. "Analysis of 2018 International Linked Data Survey for Implementers." Code4lib Journal no. 42 (November 8, 2018)ः 1. https://journal.code4lib.org/articles/13867

Vander Sande, Miel, Ruben Verborgh, Patrick Hochstenbach, and Herbert Van de Sompel. "Toward Sustainable Publishing and Querying of Distributed Linked Data Archives." Journal of Documentation 74, no. 1 (2018): 195-222.

Wahid, Nazia, Nosheen Fatima Warraich, and Muzammil Tahira. "Mapping the Cataloguing Practices in Information Environment: A Review of Linked Data Challenges." Information and Learning Science 119, no. 9 (2018): 586-596.

Wenige, Lisa and Johannes Ruhland. "Retrieval by Recommendation: Using LOD Technologies to Improve Digital Library Search." International Journal on Digital Libraries 19, no. 2/3 (September 2018): 253-69. 